\title{
Waste Glycerol as New Green Inhibition for Metal Corrosion in Acid Medium
}

\author{
Isam Al Zubaidi*, Hussameldin Ibrahim, Robert Jones, Mohammed Alzughaibi, Moayed Albayyadhi, \\ Farzad Darzi \\ Industrial Systems Engineering, Faculty of Engineering and Applied Science, University of Regina, 3737 Wascana \\ Parkway, Regina, SK \\ Isam.Al.Zubaidi@uregina.ca
}

\begin{abstract}
The inhibitive effect of (crude) waste glycerol from biodiesel manufacturing process on the corrosion behavior of steel was investigated. The inhibitory effects were studied on steel in $0.5 \mathrm{~N}$ hydrochloric acid solutions, using a weight loss method, and Scanning Electron Microscopy (SEM) techniques. The inhibition effect was studied by varying concentrations of inhibitors (0.1, 0.3, $0.5,0.8$, and $1.0 \%$ ) by weight of solution. The corrosion of steel was inhibited continuously with the amount of inhibitor added. It reached to very high level of inhibition with 0.8 and $1 \%$ of inhibitor concentration. The adsorption isotherm models were applied and it is shown that the adsorption of inhibitor layer followed Langmuir isotherm model. The Scanning Electron Microscopy showed that the inhibitor is covering the surface of the metal so that it prevents the metal surface to be in contact with the acid medium.
\end{abstract}

\section{Introduction}

The corrosion process is spontaneous process that occurs in metal as a result of oxidation and occurs over a period of time at different operating temperatures. The type of corrosion mechanism and its rate of attack depend on the exact nature of the atmosphere in which the corrosion takes place. Although the term is usually applied to metals, non metallic materials including ceramics, plastics, rubber, and wood, deteriorate at the surface to some extent when they are exposed to certain combinations of liquids and/or gases. Common examples of metal corrosion are the rusting of iron, the tarnishing of silver, the dissolution of metals in acid solutions, and the growth of patina on copper. Chemical corrosion is an important type of corrosion that occurs in transportation such as bridges, pipelines, vehicles, etc., utilities (electrical, water, telecommunications, and nuclear power plant), Industrial and manufacturing engineering industry, petroleum refinery, etc. Acid solutions are widely used in process industries as inhibitors for the removal of deposited scales from metallic surfaces. Generally the applications of corrosion inhibitors have been an accepted practice for their aggressive nature towards acids [1]. Corrosion of metals and alloys particularly in acidic media is an important industrial problem. Hydrochloric acid, which is widely used for pickling, cleaning, descaling and etching of metals, on the other hand also, contributes to the corrosion of metal surface. Money is wasted each year as a result of metallic corrosion. It is estimated that with proper corrosion prevention technologies, about 25 to $30 \%$ of this loss could be avoided [2]. One of the best methods to reduce the rate of metallic corrosion is by the addition of inhibitors; even small concentrations can result in the decrease of the corrosion rate of the metal surface [3-9]. Several conditions must be fulfilled for the selection of a suitable inhibitor; (a) the cost and amount of the inhibitors, (b) long term toxicological effects on the environment and living species, (c) the inhibitor's availability and stability in the environment. Different organic compounds can be used as corrosion inhibitors during acid pickling process [10-12].

The dramatic increase in demand for clean transportation fuels and the increase in environmental concerns, coupled with diminishing crude oil reserves, have increased the emphasis on renewable energy. Biodiesel is one of the promising alternative and renewable fuels, has been viewed with increasing interest and its production capacity has been increased in the recent years. Although world biodiesel production was expected to reach a high capacity levels but because of the high production cost and the production of waste (crude) glycerol as by product has slower the rate of production [13]. Waste (crude) glycerol is a major byproduct in the biodiesel manufacturing process in Saskatchewan / Canada. In general, for every 100 pounds of biodiesel produced, approximately 10 pounds of crude glycerol are created. Generally as an example; the fatty acid methyl ester (biodiesel) synthesis from triglycerides producing glycerol is as follows: 


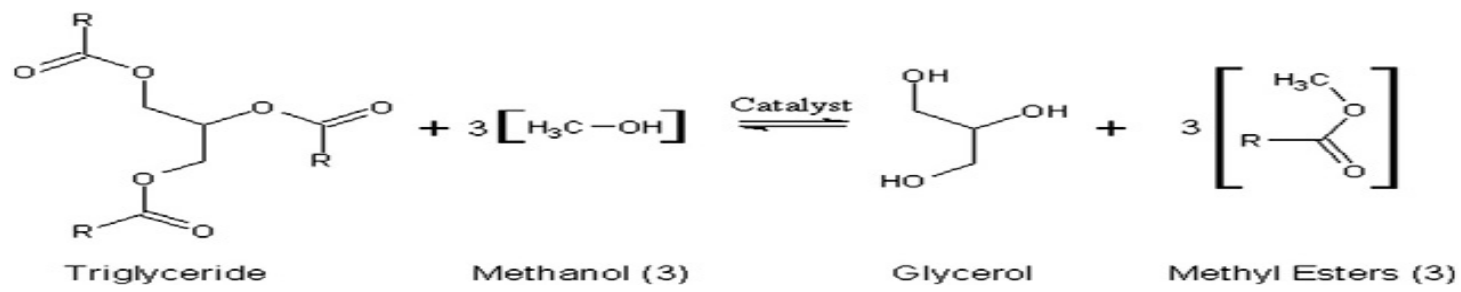

Crude glycerol is expensive to purify for use in the food, pharmaceutical, or cosmetics industries. Various methods for disposal and utilization of this crude glycerol have been attempted, including combustion, composting, anaerobic digestion, animal feeds, and thermochemical/biological conversions to value-added products. The chemical composition of crude glycerol depends on the type of catalyst used to produce biodiesel, the trans-esterification efficiency, recovery efficiency of biodiesel, other impurities in the feedstock, and whether the methanol and catalysts were recovered. The chemical composition of waste glycerol is varied, [14] reported the glycerol content ranged between $38 \%$ and $96 \%$, with some samples including more than $14 \%$ methanol and $29 \%$ ash. Hydrochloric acid is one of the most commonly used acids, among the acid solutions for acid pickling process. The replacement of toxic inhibitors by eco-friendly inhibitors for the metal protection in acidic media has been suggested in the second half of the nineteenth century. Molasses and vegetable oil were used as corrosion inhibitors for steel sheets in acid pickling process [15]. Later, Many authors have been studied the inhibition effect of different environmental friendly materials as corrosion inhibitors for stainless and mild steel corrosion in $\mathrm{HCl}$ medium [16-20].

\section{Experimental Work}

\subsection{Materials}

Steel Sample:

Steel sample of ASTM A6-13A was used for this work, which has the mechanical properties shown in Table 1, and chemical composition as shown in Table 2.

Table 1: Mechanical properties of Steel ASTM A6-13A specimen.

\begin{tabular}{|l|l|l|}
\hline Ultimate Tensile (kpsi) & Yield Strength (kpsi) & Elongation (\%) \\
\hline 72.105 & 49.870 & 21.00 \\
\hline
\end{tabular}

Table 2: Chemical Composition of Steel ASTM A6-13A specimen in (\%) by Weight.

\begin{tabular}{|l|l|l|l|l|l|l|l|l|l|l|l|}
\hline $\mathrm{C}$ & $\mathrm{Mn}$ & $\mathrm{P}$ & $\mathrm{S}$ & $\mathrm{Si}$ & $\mathrm{Cu}$ & $\mathrm{Ni}$ & $\mathrm{Cr}$ & $\mathrm{Mo}$ & $\mathrm{N}$ & $\mathrm{Pb}$ & $\mathrm{Sn}$ \\
\hline .17 & .67 & .012 & .029 & .18 & .24 & .11 & .04 & .030 & .009 & .004 & .012 \\
\hline
\end{tabular}

The steel specimen was carefully polished by a fine sand paper and washed several times with distilled water. Then it was cleaned from any greasing materials by heptane, washing with distilled water, and then cleaned acetone followed by washing with distilled water. The sample was wiped with clean tissues and dried completely by electrical dryer.

Waste biodiesel as corrosion inhibitor was obtained from one of the biodiesel production project at University of Regina/ Canada. It is a liquid with brownish color material.

\subsection{Experimental procedure}

The standard solution of $\mathrm{HCl}$ of $0.5 \mathrm{~N}$ has been prepared carefully. The steel specimen was polished to remove any dirt or greasy material by choosing the fine sand paper followed by water washing and then chemical washing. The chemical washing was performed by immersing in heptane followed by washing with water and then cleaning with acetone. The specimen was dried your hair dryer. The dimension of specimen was determined using vernier caliper and weighted using very precise analytical balance. The specimen was immersed in the acid medium and the corrosion rate of 
steel was determined by measuring the weight loss with time. The corrosion rate of mild steel was determined using the relation

$$
W=\frac{\Delta m}{S \times t}
$$

Where $\Delta \mathrm{m}$ is the mass loss $(\mathrm{g}), \mathrm{S}$ the area $(\mathrm{m} 2)$ and $\mathrm{t}$ is the immersion period $(\mathrm{hr})$. The gravimetric method (weight loss) is probably the most widely used method of inhibition assessment [21-23]. The simplicity and reliability of the measurement offered by the weight loss method is such that the technique forms the baseline method of measurement in many corrosion-monitoring programmers.

The inhibitor was introduced with different concentration and the corrosion rate was measured. The effect of addition of waste glycerol on the corrosion of steel in $1 \mathrm{M} \mathrm{HCl}$ solution was studied by weight loss at $298 \mathrm{~K}$ at various immersion periods. Inhibition efficiency (IE \%) and the degree of surface coverage, $\theta$, of investigated inhibitor for the corrosion of steel in $\mathrm{HCl}$ were calculated as follows [24]:

$$
\% \mathrm{IE}=\theta \times 100=[(\mathrm{Wo}-\mathrm{W}) / \mathrm{Wo}] \times 100
$$

Where $\mathrm{W}_{\mathrm{o}}$ and $\mathrm{W}$ are the values of the average weight losses in the absence and presence of the waste glycerol inhibitor, respectively. The primary action of inhibitors in acid solution is generally suggested to be adsorption on the metal surface. This involves the assumption that the corrosion reactions are prevented from occurring over the area (or active sites) of the metal surface covered by adsorbed inhibitor species and the corrosion reaction occurred mainly on the inhibitor free area [25]. The surface coverage $(\theta)$ data is very important in discussing the adsorption characteristics of the inhibitor material. When the fraction of surface covered is determined as a function of the concentration at specific constant temperature, adsorption isotherm could be evaluated at equilibrium condition. The Langmuir's isotherm suggested the dependence of the fraction of the surface covered $\theta$ on the concentration of the inhibitor $\mathrm{C}$ according to the following equation:

$$
\frac{C}{\theta}=\frac{1}{K}+C
$$

Where $\mathrm{C}$ is the equilibrium inhibitor concentration, $\mathrm{K}$ adsorptive equilibrium constant, representing the degree of adsorption (i.e., the higher the value of $\mathrm{K}$ indicates that the inhibitor is strongly adsorbed on the metal surface). The linear plot of $\mathrm{C} / \theta$ versus $\mathrm{C}$ must be obtained to obey this adsorption assumption.

\section{Results and Discussion}

\subsection{Corrosion of metals}

The dimensions of the steel specimen was measured using a vernier caliper and weighed precisely, hanged with noncorrosion material and then immersed in $0.5 \mathrm{~N} \mathrm{HCl}$ solution for different times. In each time interval, the specimen was cleaned, dried, and weighed precisely. The weight loss method was used to investigate the corrosion rate. The mass of steel specimen was reduced with time as shown in Figure 1. The \% mass loss with time is shown in Figure 2 . The $\%$ mass loss was initially increased slowly due to the remaining oxidation layer on the surface of the steel specimen although polishing and chemical cleaning was subjected to the steel specimen before immersing the specimen in acid medium. The $\%$ mass loss was then increased rapidly due to the breakage of this layer and the surface of the specimen was in contact directly to the acid material. Figure 3 showed the rate of corrosion of steel specimen and it is clear that the corrosion rate decreased with time. This is in concise with all corrosion studies. 


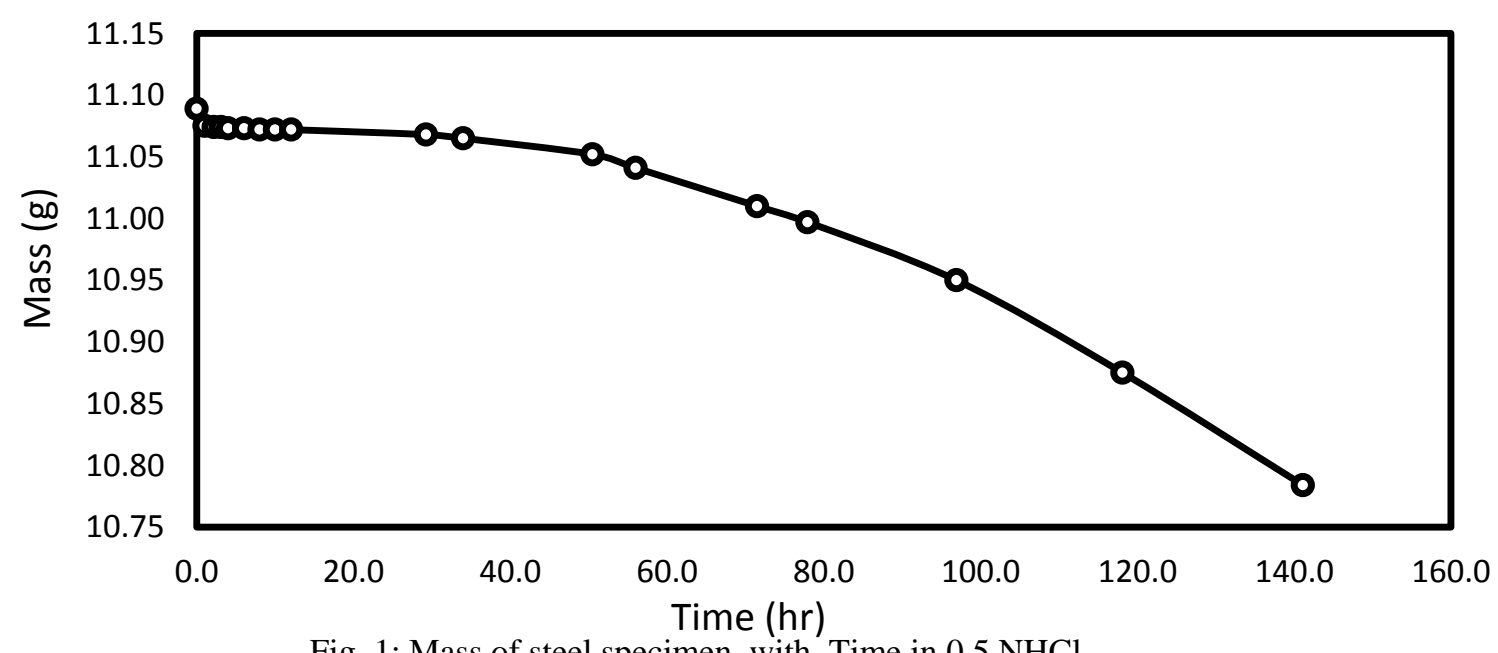

Fig. 1: Mass of steel specimen with Time in $0.5 \mathrm{NHCl}$.

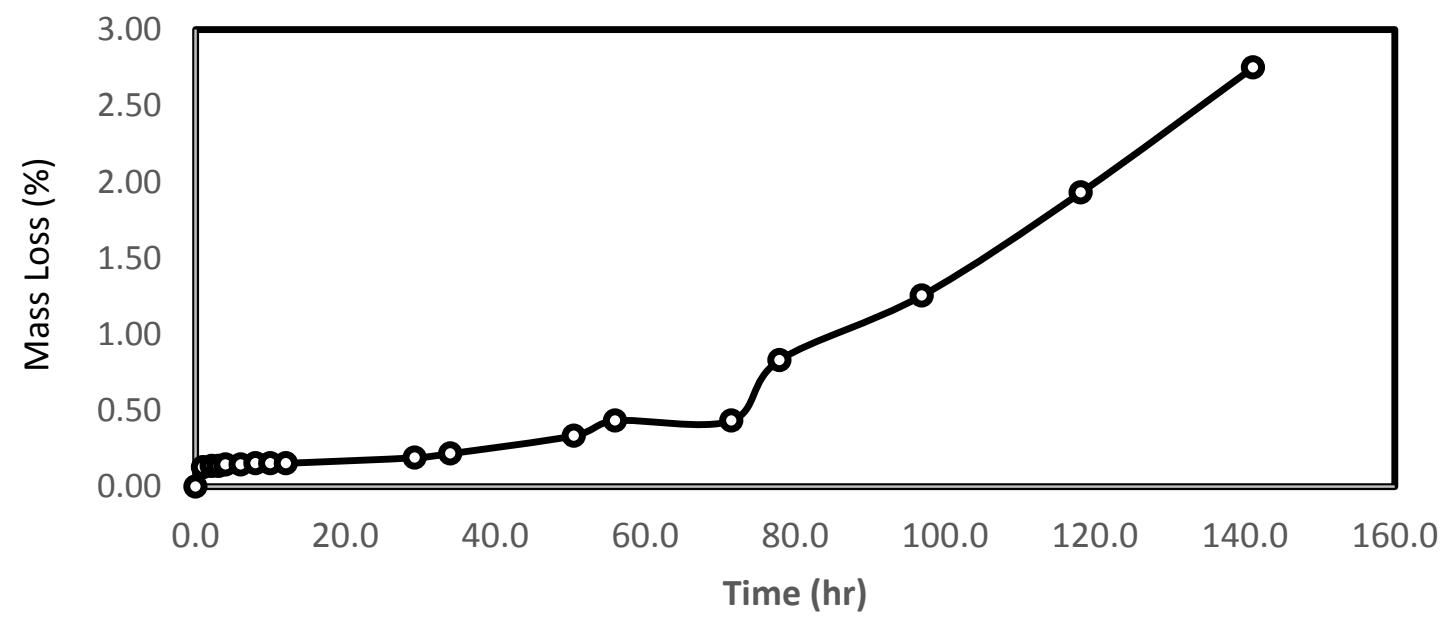

Fig. 2: Mass Loss (\%) Vs. Time for steel specimen.

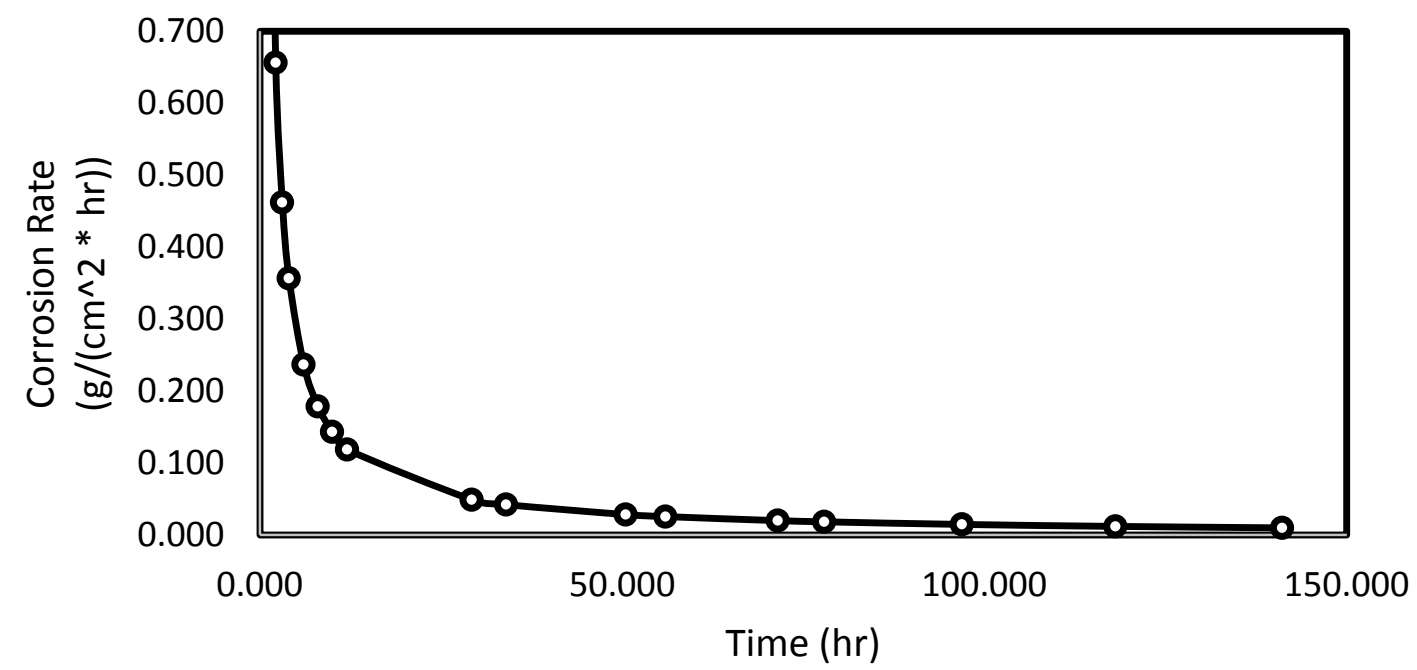

Fig. 3: Corrosion Rate of steel specimen in $0.5 \mathrm{~N} \mathrm{HCl}$ vs. time. 


\subsection{Waste glycerol as inhibitor}

Crude glycerol was used without any treatment and added to the $0.5 \mathrm{~N} \mathrm{HCL}$ solutions as weight percent. Different weight percent were used, $0.1 \%, 0.3 \%, 0.5 \%, 0.8 \%$, and $1 \%$ by weight. It believed that this small quantity of inhibitor would not have a significant effect of acid performance in a pickling process for steel specimen to remove any scale in industrial engineering applications. The corrosion inhibition efficiency of crude glycerol and the inhibition surface coverage was calculated. The inhibition efficiency of (IE\%) was plotted as function of time for the different inhibitor concentration as shown in Figure 3. The inhibition efficiency was increased with the amount of inhibitor added to the acid. This can be attributed to the high adsorption layer that may cover the surface of the steel specimen. The inhibition efficiency reached to very high levels with $0.8 \%$ and $1 \%$ by weight of the amount of acid. The Langmuir adsorption isotherm model was applied as shown in Figure 4. The high $\mathrm{R}^{2}$ value of 0.985 is shown that this adsorption model can be applied for this inhibitor. The $\mathrm{K}$ adsorptive equilibrium constant is equal to 0.387 .

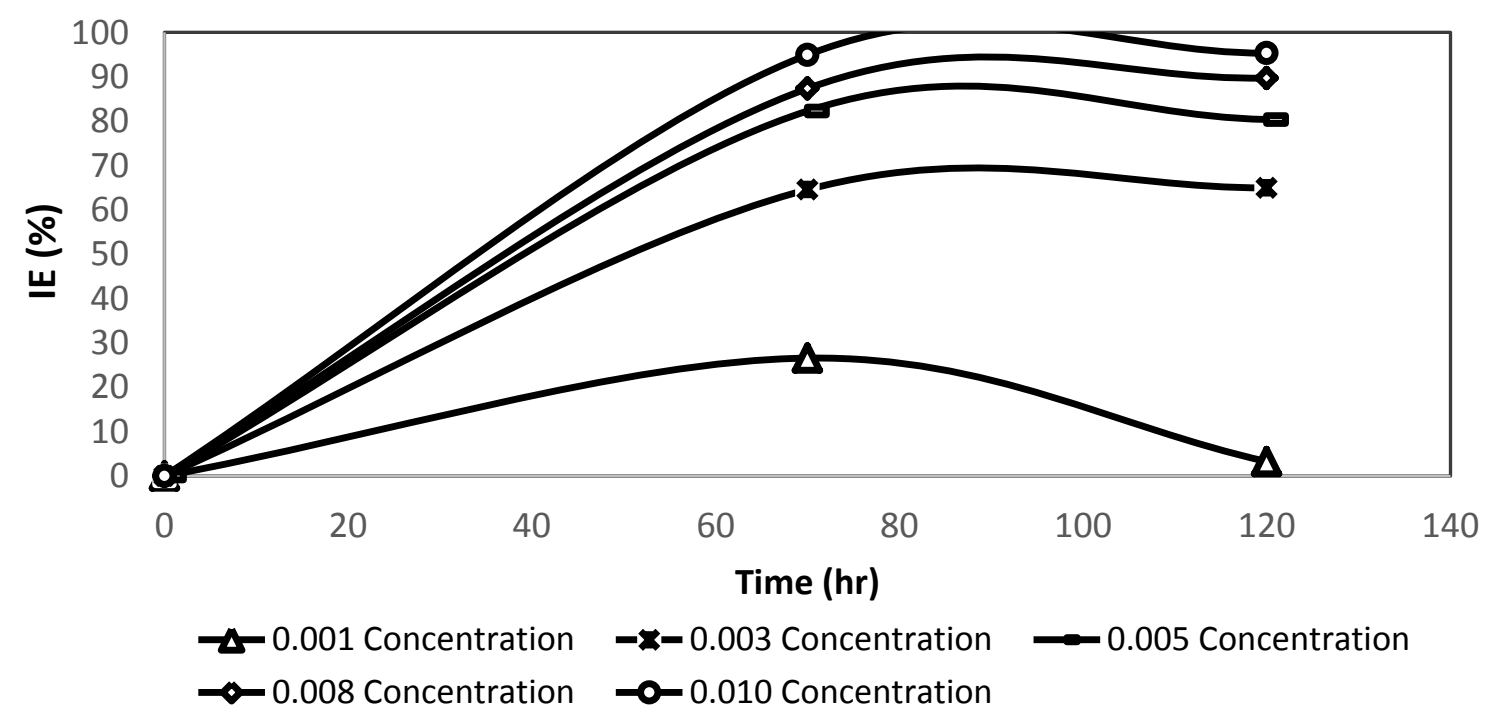

Fig. 4: Inhibitor Efficiency of waste glycerol with time Time in wt \% of inhibitor.

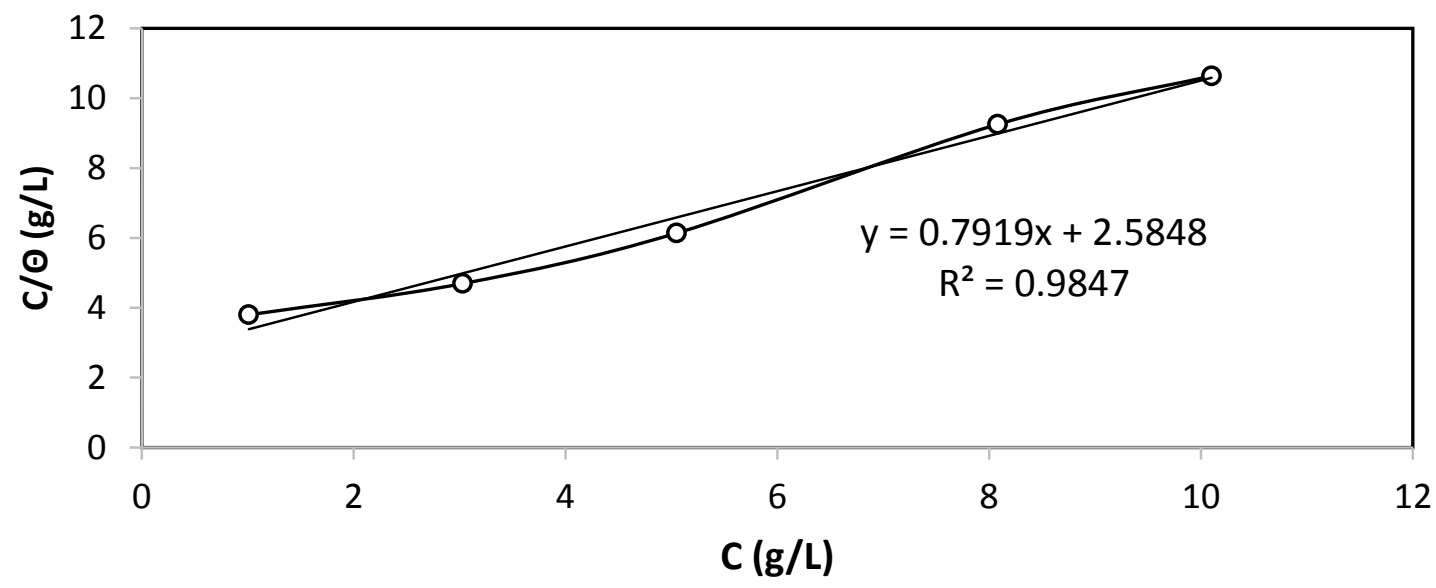

Fig. 5: C/@ VS. C after 70 Hrs.

\subsection{SEM study}

Scanning Electron Microscopy images were taken for new steel specimen, steel specimen after corrosion using $0.5 \mathrm{~N}$ $\mathrm{HCl}$ medium, and after corrosion inhibition with different concentrations of waste glycerol to investigate the changes 
occurred on the surface of steel specimen after 3 days immersing hydraulic acid and hydraulic acid with different concentrations of waste glycerol. These images are shown in Figure 5. Steel surface is severely damaged and rough due to an aggressive attack of the corroding medium. Figure 5C reveals that the corrosion marks on the inhibited samples decrease in presence of waste glycerol, which has the ability to adsorb on the surface of steel specimen. The layer of the adsorbed layer was become thicker with the concentration of the inhibitor. Moreover the parallel lines on the carbon steel surface can be attributed to polishing scratches.

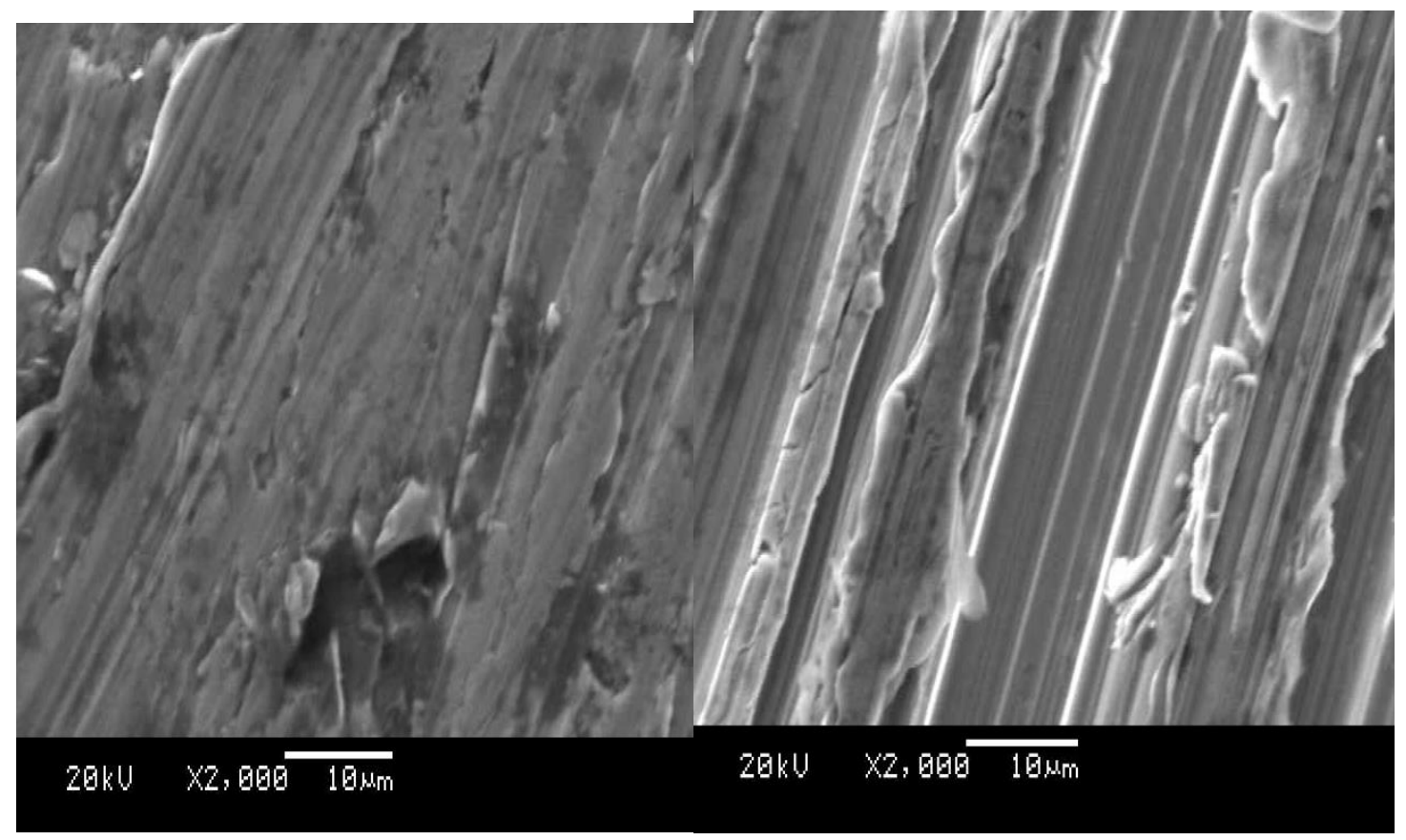

(A)

(B)

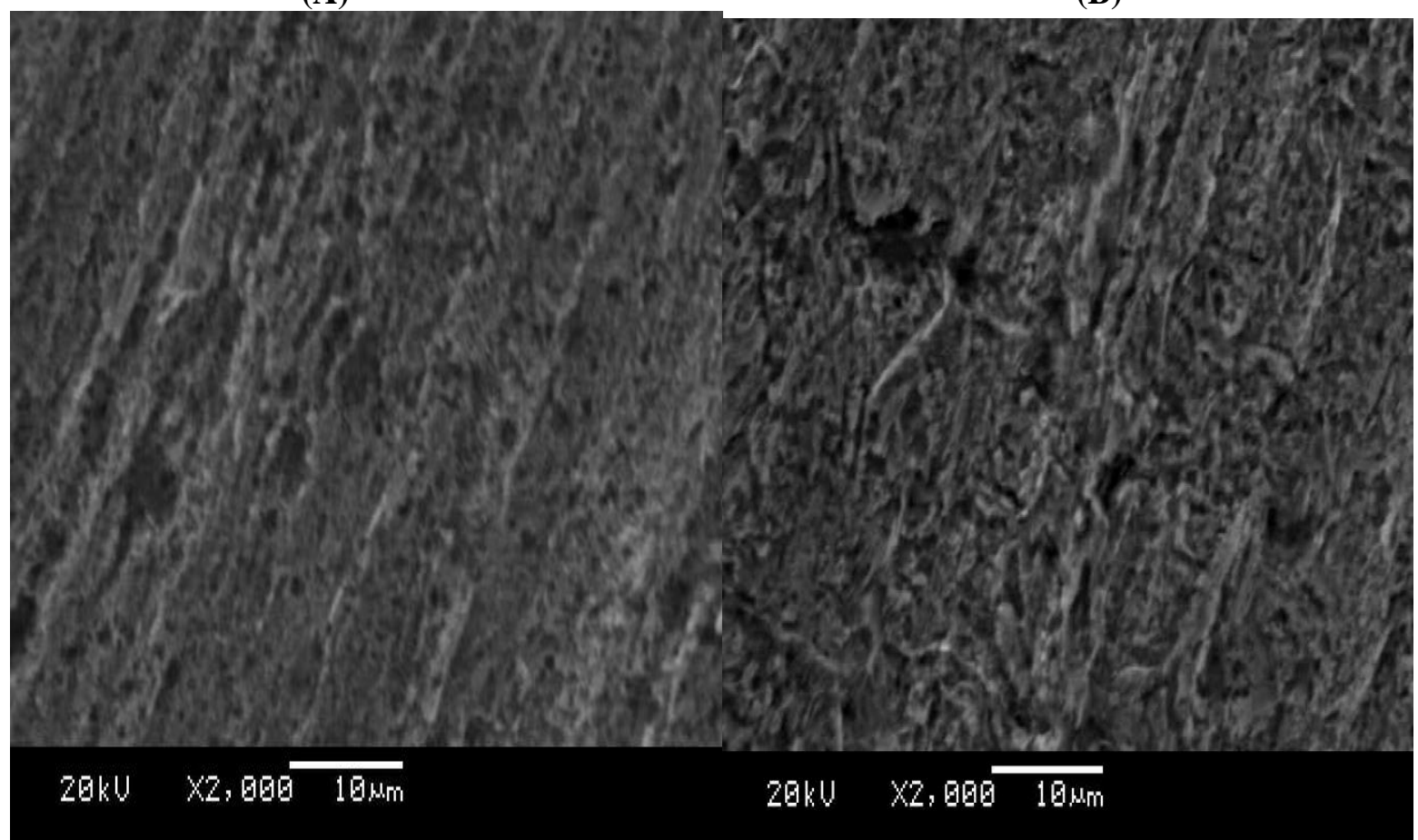

(C)

(D)

Fig. 6: SEM images A) new steel specimen, B) corrosion of steel specimen with $0.5 \mathrm{~N} \mathrm{HCl}, \mathrm{C}$ ) After corrosion inhibition with $0.3 \%$ by wt waste glycerol, D) after corrosion inhibition with $0.5 \%$ wt waste glycerol. 


\section{Conclusion}

The corrosion of steel was studied in an acid medium of $0.5 \mathrm{~N} \mathrm{HCl}$. The weight loss as well as scanning electron microscopy was used for this study. The crude (waste) glycerol was introduced as new corrosion inhibitor for acid medium with steel specimen. The corrosion inhibition effect was reached to very high levels with the amount of crude glycerol added. This is ongoing project and more work will performed for using this inhibitor for different metals and different medium.

\section{Acknowledgement}

The authors would like to thank the University of Regina, Program of Industrial System Engineering for providing all the facilities to achieve this work. Extended thank to the Engineering workshop for providing the specimen to achieve this work.

\section{References}

[1] G. Khan, K. Md. S. Newaz, W. J. Basirun, H. B. M. Ali, F. L. Faraj, and G. M. Khan, "Application of Natural Product Extracts as Green Corrosion Inhibitors for Metals and Alloys in Acid Pickling Processes: A review," Int. J. Electrochem. Sci., vol. 10, pp. 6120 - 6134, 2015.

[2] H. K. Gerhardus, P. H. Michiel, N. G. Bronger, Y. Thompson, V. Paul, and J. H. Payer, "Corrosion Cost and Preventive Strategies in the United States. Supplement to Materials Performance," Report No. FHWA. RD-01-156, Federal Highway Administration, Mclean, 2002.

[3] M. Bouklah, B. Hammouti, M. Lagrenée, and F. Bentis, "Thermodynamic properties of 2,5-bis(4-methoxyphenyl)1,3,4-oxadiazole as a corrosion inhibitor for mild steel in normal sulfuric acid medium," Corrosion Science, vol. 48, no. 9, pp. 2831-2842, 2006.

[4] P. B. Raja and M. G. Sethuraman, "Natural products as corrosion inhibitor for metals in corrosive media-a review," Materials Letters, vol. 62, no. 1, pp. 113-116, 2008.

[5] L. Wang, J.-X. Pu, and H.-C. Luo, "Corrosion inhibition of zinc in phosphoric acid solution by 2mercaptobenzimidazole," Corrosion Science, vol. 45, no. 4, pp. 677-683, 2003.

[6] A. Y. EL-Etre, "Natural honey as corrosion inhibitor for metals and alloys, Copper in neutral aqueous solution," Corrosion Science, vol. 40, no. 11, pp. 1845-1850, 1998.

[7] I. Radojcic, K. Berkovic, S. Kovac, and J. Vorkapic-Furac, "Natural honey and black radish juice as tin corrosion inhibitors," Corrosion Science, vol. 50, pp. 1498-1504, 2008.

[8] Z. Ahmad, Principles of Corrosion Engineering and Corrosion Control. Elsevier, Oxford, 2006.

[9] P. R. Roberge, Handbook of Corrosion Engineering, McGraw-Hill, New York, 2000.

[10] S. A. Ali, H. A. Al-Muallem, S. U. Rahman, and M. T. Saeed, "Bis-isoxazolidines: A new class of corrosion inhibitors of mild steel in acidic media," Corrosion Science, vol. 50, pp. 3070-377, 2008.

[11] B. Mernari, H. El Attari, M. Traisnel, F. Bentiss, and M. Lagrenee, "Inhibiting effects of 3, 5-bis(n-pyridyl)-4-amino1,2,4-triazoles on the corrosion for mild steel in $1 \mathrm{M} \mathrm{HCl}$ medium," Corrosion Science, vol. 40, pp. 391-399, 1998.

[12] M. El Achouri, S. Kertit, H. M. Gouttaya, B. Nciri, Y. Bensouda, L. Perez, M. R. Infante, and K. Elkacemi, "Corrosion inhibition of iron in $1 \mathrm{M} \mathrm{HCl}$ by some gemini surfactants in the series of alkanediyl- $\alpha, \omega$-bis-(dimethyl tetradecyl ammonium bromide)," Progress in Organic Coatings, vol. 43, no. 4, pp. 267-273, 2001.

[13] F. Yang, M. A. Hanna, and R. Sun, "Value-added uses for crude glycerol-a byproduct of biodiesel production," Biotechnology for Biofuels, vol. 5, no. 13, 2012.

[14] B. R. Bewley, A. Berkaliev, H. Henriksen, D. B. Ball, and L. S. Ott, "Waste glycerol from biodiesel synthesis as a component in deep eutectic solvents," Fuel Processing Technology, vol. 138, pp. 419-423, 2015.

[15] C. F. Hansen, A. Hernandez, B. P. Mullan, K. Moore, M. Trezona-Murray, R. H. King, and J. R. Pluske, "A chemical analysis of samples of crude glycerol from the production of biodiesel in Australia, and the effects of feeding crude glycerol to growing-finishing pigs on performance, plasma metabolites and meat quality at slaughter," Anim Prod Sci, vol. 49, pp. 154-161, 2009.

[16] D. Kesavan, M. Gopiraman, and N. Sulochana, "Green Inhibitors for Corrosion of Metals: A Review," Che Sci Rev Lett, vol. 1, no. 1, pp. 1-8, 2012. 
[17] A. S. Yaro, A. A. Khadom, and R. K. Wael, "Apricot juice as green corrosion inhibitor of mild steel in phosphoric acid," Alexandria Engineering Journal, vol. 52, pp. 129-135, 2013.

[18] M. Sangeetha, S. Rajendran, T. S. Muthumegala, and A. Krishnaveni, "Green corrosion inhibitors-An Overview" ZAŠTITA MATERIJALA, vol. 52, 2011.

[19] A. S. Fouda, G. Y. Elewady, K. shalabi, and S. Habouba, "Anise Extract as Green Corrosion Inhibitor for Carbon Steel in Hydrochloric Acid Solutions," International Journal of Innovative Research in Science, Engineering and Technology, vol. 3, no. 4, pp. 11210-11228, 2014.

[20] A. S. Fouda, G. Y. Elewady, K. Shalabi, and S. Habbouba, "Gibberellic acid as green corrosion inhibitor for carbon steel in hydrochloric acid solutions," J. Mater. Environ. Sci., vol. 5, no. 3, pp. 767-778, 2014.

[21] I. B. Obot and N. O. Obi-Ebbed, "2, 3-Diphenylbenzoquinoxaline: A new corrosion inhibitor for mild steel in sulphuric acid," Corrosion Science, vol. 52, pp. 282- 285, 2010.

[22] I. B. Obot, N. O. Obi-Egbedi, and N. W. Odozi, "Acenaphtho [1,2-b] quinoxaline as a novel corrosion inhibitor for mild steel in 0.5 M H2SO4," Corrosion Science, vol. 52, pp. 923- 926, 2010.

[23] I. B. Obot and N. O. Obi-Egbedi, "Indeno-1-one [2, 3-b]quinoxaline as an effective inhibitor for the corrosion of mild steel in 0.5 M H2SO4 solution," Mater. Chem. Phys., vol. 122, pp. 325-328, 2010.

[24] E. E. Oguzie, "Corrosion inhibition of mild steel in hydrochloric acid solution by methylene blue dye," Mater. Letters, vol. 59, pp. 1076-1079, 2005.

[25] L. L. Shreir, R. A. Jarman, and G. T. Burstein, Corrosion, vol. 2, $3^{\text {rd }}$ Ed. Newnes-Butterworths, London, 1994. 